\title{
Parental consent to cosmetic facial surgery in Down's syndrome
}

R B Jones Retired Consultant Paediatrician, London

\begin{abstract}
It is suggested that the practice of attempting to normalise children with Down's syndrome by subjecting them to major facial plastic surgery has no therapeutic benefit, and should be seen as mutilating surgery comparable to female circumcision.

(Fournal of Medical Ethics 2000;26:101-102)

Keywords: Down's syndrome; cosmetic surgery; parental consent; female circumcision; male circumcision
\end{abstract}

A recent television documentary ${ }^{1}$ was devoted to the use of cosmetic plastic surgery in people with Down's syndrome. This, it was claimed was of great benefit to them, in that, by normalising their appearance, the prejudice that they met because of their appearance and the diagnosis made evident by it, would be lessened, and they would thereby have an easier life. Although major surgery including bony reconstruction of the face was involved, no one in the programme suggested that there was any reason for the surgery, other than to influence the response of society at large to the patient. It was not for example, suggested that there was any improvement in function as a result, so that it cannot be compared with, say, cleft lip or palate repair, in which, although major social advantages result from the cosmetic improvement, equally great benefits result from the functional improvement obtained.

The surgery was therefore being undertaken solely because of society's perceived response to people with Down syndrome. If there was no stigma attached to the diagnosis, or if the facial appearance was not characteristic, then there would be no indication for surgery. There is however, no clear consensus that, even if the surgery was effective in eradicating the characteristic appearance, which judging from the patients shown in the programme, it was not, this would improve the response. Is the response in fact thought to be so negative? Pueschel et $a l^{3}$ for example, in a survey of parents found that $72 \%$ were not concerned about the effect of the child's appearance, and $83 \%$ felt that the child was well accepted by society. Olbrisch ${ }^{2}$ on the other hand, claims there is benefit in that children with Down's syndrome are stigmatised by their appearance, and are thought to look stupid. It could be argued that this could affect their psychological adjustment. This view is not borne out by the findings of Lansdown and Polak. ${ }^{4}$ They were able to show that although when asked, children were more likely to reject pictures of children with cleft lip or protruding teeth than pictures of children without deformity, children who themselves had had a cleft lip repaired showed no more overt disturbed behaviour than did children without facial deformity. It must be accepted that there is less stigma attached to cleft lip or protruding teeth than to Down's syndrome, however, Lansdown and Polak's findings do suggest that facial appearance is not a big factor in psychological adjustment. In a second study, Lansdown et $a \bar{l}$ were able to show that if children were ranked as having mild, moderate or severe deformity, those with the severe deformity adjusted best; it is suggested that because they were so used to a negative reaction it did not upset them. If this were applied to the usefulness of cosmetic surgery in Down's syndrome, it would suggest that far from being beneficial this could actually hinder psychological adjustment.

What then is the function of the surgery? A recurring theme of the television programme was that it made the children "more normal"; that it "normalised" them. The overriding function therefore seemed to be to make the children conform more closely to what the parents conceived of as the norms of their society, and therefore to make them acceptable in that society. Apart from the one patient shown who was an adult, none of the patients in the programme were old enough to give consent to the surgery on their own behalf, and since it was of no direct benefit to them, it 
must be questioned whether the parents had the right to consent for them. I have argued elsewhere ${ }^{6}$ that on the related issue of consent to the use of children in publicity material such as medical television documentaries, if it is not possible to demonstrate personal benefit to the child, or that the public interest is in any way served, consent cannot be given for the child by the parent, (or anyone else for that matter). Consent to non-therapeutic surgery is in my opinion comparable to consent to publicity since no public or personal benefit accrues from it.

In considering the implications of facial surgery for children with Down's syndrome a parallel can be drawn with another form of surgery undertaken in order that the child may conform to the norms of the society in which he or she lives: circumcision. Most discussion of this topic centres on female circumcision, a procedure practised in some African societies, usually, but not exclusively Muslim. This may vary from relatively minor clitoral surgery to major removal of the entire vulva. ${ }^{7}$ However, Abu-Sahlieh ${ }^{8}$ argues that there is no difference between this and male circumcision when performed as a rite of passage by Jews and Muslims. Female circumcision is never performed for therapeutic reasons, and male circumcision only rarely so. It is performed because the parents believe that the child will be unable to function in his or her society without it. In this respect it is entirely comparable to facial surgery in Down's syndrome. Although there is little outcry against male circumcision, female circumcision is illegal in many Western countries where it is seen as a gross lifelong mutilation and assault which constitutes an abuse of the child. In that facial surgery in Down's syndrome is often equally major, painful and always therapeutically unnecessary, consideration should be given to outlawing it also.

R B fones, FRCP, FRCOphth, FRCPCH, is a Retired Consultant Paediatrician. Address for correspondence: 17 Dartmouth Row, London.

\section{References}

1 Changing faces. Carlton Television, 24 Nov 98.

2 Olbrisch RR. Plastic surgical management of children with Down syndrome: indications and results. British fournal of Plastic Surgery 1982;35:195-200.

3 Pueschel SM, Monteiro LA, Erickson M. Parents' and physicians' perception of facial plastic surgery in children with Down syndrome. Fournal of Mental Deficiency Research 1986;30:71-9.

4 Lansdown R, Polak L. A study of the psychological effects of facial deformity in children. Child Care, Health and Development 1975;1,2:65-91.

5 Lansdown R, Lloyd J, Hunter J. Facial deformity in childhood: severity and psychological adjustment. Child Care, Health and Development 1991; 17,3:165-71.

6 Jones RB. Parental consent to publicity. Fournal of Medical Ethics 1999;25:379-8.

7 Knott L. Female circumcision in Britain. Maternal and Child Health 1996;21,5:127-9.

8 Abu-Sahlieh SAA. To mutilate in the name of Jehovah or Allah: legitimization of male and female circumcision. Medicine $\mathcal{E}$
Law 1994;13:575-622. 